\title{
Evaluation of promising technologies for soil salinity amelioration in Timpaki (Crete): a participatory approach
}

\author{
I. S. Panagea ${ }^{1}$, I. N. Daliakopoulos ${ }^{1}$, I. K. Tsanis ${ }^{1,2}$, and G. Schwilch ${ }^{3}$ \\ ${ }^{1}$ School of Environmental Engineering, Technical University of Crete, Chania, Greece \\ ${ }^{2}$ Department of Civil Engineering, McMaster University, Hamilton, Ontario, Canada \\ ${ }^{3}$ Centre for Development and Environment, University of Bern, Bern, Switzerland \\ Correspondence to: I. N. Daliakopoulos (daliakopoulos@hydromech.gr)
}

Received: 9 September 2015 - Published in Solid Earth Discuss.: 6 October 2015

Revised: January 2016 - Accepted: 11 January 2016 - Published: 3 February 2016

\begin{abstract}
Soil salinity management can be complex, expensive, and time demanding, especially in arid and semi-arid regions. Besides taking no action, possible management strategies include amelioration and adaptation measures. Here we apply the World Overview of Conservation Approaches and Technologies (WOCAT) framework for the systematic analysis and evaluation and selection of soil salinisation amelioration technologies in close collaboration with stakeholders. The participatory approach is applied in the RECARE (Preventing and Remediating degradation of soils in Europe through Land Care) project case study of Timpaki, a semiarid region in south-central Crete (Greece) where the main land use is horticulture in greenhouses irrigated by groundwater. Excessive groundwater abstractions have resulted in a drop of the groundwater level in the coastal part of the aquifer, thus leading to seawater intrusion and in turn to soil salinisation. The documented technologies are evaluated for their impacts on ecosystem services, cost, and input requirements using a participatory approach and field evaluations. Results show that technologies which promote maintaining existing crop types while enhancing productivity and decreasing soil salinity are preferred by the stakeholders. The evaluation concludes that rainwater harvesting is the optimal solution for direct soil salinity mitigation, as it addresses a wider range of ecosystem and human well-being benefits. Nevertheless, this merit is offset by poor financial motivation making agronomic measures more attractive to users.
\end{abstract}

\section{Introduction}

Soil, as a control on the biogeochemical and hydrological cycles of the Earth system and a provider of vital goods and services to sustain life, is one of our most important natural resources (Berendse et al., 2015; Brevik et al., 2015; Keesstra et al., 2012). Soil salinisation - a term used to refer comprehensively to saline, sodic, and alkaline soils (van Beek and Tóth, 2012) - is one of the major soil degradation threats globally, especially in drylands. In advanced stages salinisation transforms fertile and productive fields to barren land, thus restraining any vegetation growth (Chesworth, 2008; Jones et al., 2012; Tóth et al., 2008). High levels of soil salt accumulation can impact agricultural production, environmental health, and economic welfare (Rengasamy, 2006). Globally, $34 \mathrm{Mha}$ - about $11 \%$ of total irrigated land - is estimated to be impacted (Montanarella, 2007). Salinisation is often linked to arid irrigated lands where prevailing low rainfall, high evapotranspiration rates and soil characteristics impede soil leaching, thus causing salt to accumulate in the upper layers (Chesworth, 2008; Maas et al., 1999; MateoSagasta and Burke, 2011). While moderate problems are reported even when irrigating with water of sufficient quality, constant or increasing soil salinity is chiefly caused by the use of highly saline irrigation water such as groundwater suffering from seawater intrusion (Dubois et al., 2011; Geeson et al., 2003; Mateo-Sagasta and Burke, 2011; Tóth and Li, 2013; van Camp et al., 2004).

Soil salinity is a major factor limiting crop production and land development in coastal areas ( $\mathrm{Li}$ et al., 2012; Sparks, 2003) and is a major cause of desertification in the Mediter- 
ranean countries. Along the Mediterranean coast, the problem of soil salinity is increasing due to scarcity of precipitation and irrigation with low-quality water. Saline soils here are present mainly due to human activities (Abu Hammad and Tumeizi, 2012; Domínguez-Beisiegel et al., 2013), especially with the extension of irrigation and the unmanaged use of saline water. In the Mediterranean region, $25 \%$ of irrigated agricultural land is affected by a significant level of salinisation leading to soil degradation (Geeson et al., 2003; Mateo-Sagasta and Burke, 2011). Water supply in Greece is largely derived from groundwater sources, and about $9 \%$ of the approximately $1.4 \mathrm{Mha}$ of irrigated land is affected by soil salinisation due to seawater intrusion (Jones et al., 2003; OECD, 2009). Seawater intrusion in most coastal areas of Greece has progressed a great distance inland, especially in the south, which is characterised by a more arid climate (Daskalaki and Voudouris, 2008). The island of Crete (Fig. 1) is no exception to the problem, with intensive agriculture and high tourism activity being the two prime factors that strongly impact upon the available water resources. Agricultural growth in the Messara Plain of Crete has significantly impacted the water resources and ecosystem services of the area by substantially increasing groundwater demand (Daliakopoulos and Tsanis, 2014). The problem is exacerbated by poorly managed or unmanaged groundwater extraction and distribution as well as arid climatic conditions. Seawater intrusion in the coastal aquifer of Timpaki (Paritsis, 2005; Vafidis et al., 2013) adversely affects both water resources and soil.

Sustainable land management (SLM) solutions for the problem of soil salinisation largely depend on water availability, climatic conditions, period of salinity, land use and type of assets under threat, the current extent and rate of the threat, and the availability of resources (capital, inputs). Measures can be applied in conjunction with a wide range of amelioration methodologies (Ali, 2011; Qadir et al., 2000) which can nevertheless be very case specific. A brief account of such methodologies towards soil and water sustainability is presented in Table 2. The adoption of SLM practices depends on personal, sociocultural, socio-economic, institutional, and biophysical factors (Illukpitiya and Gopalakrishnan, 2004) rather than technical ones (Kessler, 2006). The range of variables that affect adoption may have contrasting effects depending on context (Liu et al., 2013), and while economic incentives (e.g. Posthumus and Morris, 2010) and accounting for risks, effectiveness, time, and effort involved in implementation strongly influence SLM technology adoption (e.g. Sattler and Nagel, 2010), subjective user preference may be equally or more important (e.g. Wauters et al., 2010). The World Overview of Conservation Approaches and Technologies (WOCAT, 2008) global network has been established to assist SLM specialists and practitioners from all over the world in sharing valuable knowledge and improving decision-making concerning alternative SLM practices (Liniger and Critchley, 2007; Schwilch et al., 2011), thus eventually facilitating SLM adoption. A review of the WOCAT database reveals that 10 out of 11 documented measures for soil salinity amelioration or adaptation cover agronomic, vegetative, or management rather than structural measures (WOCAT, 2015). While this is by no means a representative sample, it points to a preference of the stakeholders for low-cost, decentralised, and self-sustained solutions. Besides, stakeholder-inclusive decision making against soil salinity is currently gaining popularity (e.g. Bowmer, 2014; Hornidge et al., 2011; Lázár et al., 2015; Schultz et al., 2007) around the world. Through global sharing of successful (or failed) SLM experiences by researchers, technicians, planners, and end users involved in combating soil degradation, WOCAT strives to augment efficiency in the application of knowledge and funds for improved decision making and optimised land management.

The RECARE (Preventing and Remediating degradation of soils in Europe through Land Care) FP7 project aims to develop effective prevention, remediation, and restoration measures using an innovative transdisciplinary approach, actively integrating and advancing knowledge of stakeholders and scientists in 17 case studies, covering a range of soil threats in different biophysical and socio-economic environments across Europe. RECARE uses WOCAT to identify prevention, remediation, and restoration measures currently used to combat soil salinisation in Greece (among other soil threats at 16 other European sites). In this context, and towards an interdisciplinary approach on soil research (Brevik et al., 2015), this work assesses and discusses a stakeholder involving selection process for the application of promising technologies for soil salinity amelioration, focused at greenhouses cultivations of Timpaki, Crete.

\section{Methodology}

\subsection{The WOCAT Technology Questionnaire}

The WOCAT Technology Questionnaire (QT) defines SLM technologies as "agronomic, vegetative, structural and/or management measures that prevent and control land degradation and enhance productivity in the field". These solutions may include mechanical structures (e.g. terraces, check dams, contour stone walls, and contour ridges), biological structures (e.g. afforestation and strips of vegetation), manipulation of the surface soil (e.g. tillage; mulching; and soil amendments such as surfactants, compost, and animal and green manure), rainwater harvesting (e.g. reservoirs and retaining dams), agronomic measures (e.g. drought-resistant species and varieties, short-cycle varieties, crop rotation, animal and green manures, appropriate fertiliser use, compost, and weed control), and management measures (e.g. timing and intensity of agricultural activities, grazing management).

The QT describes case studies from the field and is always linked to a specific area where the technology is ap- 


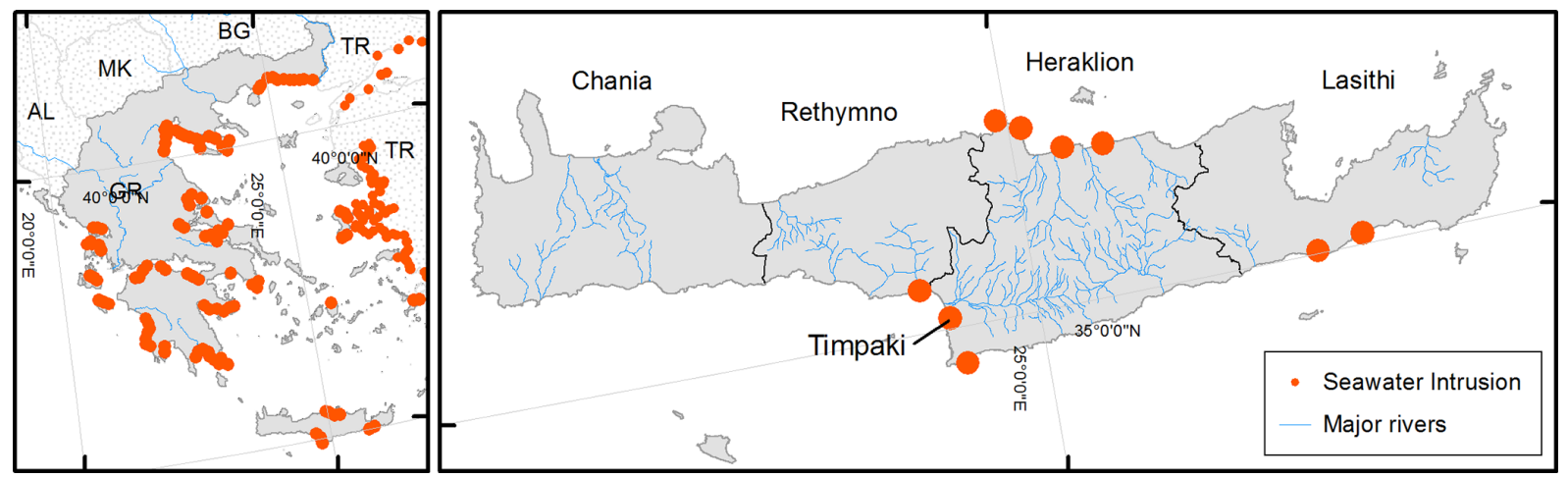

Figure 1. Areas of seawater intrusion in Greece (left) and specifically in Crete (right). Adopted from Daskalaki and Voudouris (2008) and EEA (1999).

plied and to SLM specialists who provide the information. It addresses the specifications of the technology (purpose, classification, design, and costs) and the natural and human environment where it is used. It also includes an analysis of the benefits, advantages and disadvantages, economic impacts, acceptance, and adoption of the technology (Schwilch et al., 2009). The collection of information involves personal contacts and knowledge sharing between land users and SLM specialists. The immediate benefits of filling in the questionnaires include the compilation of fragmented information often consisting of the undocumented experiences of land users and specialists - and a sound evaluation of one's own SLM activities (Liniger and Schwilch, 2002) so that they can be retrieved and suggested under similar biophysical, socioeconomic, and institutional conditions.

\subsection{Stakeholder interaction}

The stakeholder interaction methodology presented here starts with a participatory identification of actual and potential prevention, remediation, and restoration measures during a stakeholder workshop where a first selection of promising measures is made. At this workshop, participating scientists also propose soil salinisation prevention/amelioration measures documented in the literature (adopted to the case study conditions) to ensure sufficiently sound alternatives are available, while stakeholders provided measures form their personal experience. Feasible and promising measures are singled out during the workshop, and WOCAT questionnaires for SLM technologies are used to document them. Knowledge gaps and ambiguities are clarified via personal communications with experts.

At a subsequent workshop documented technologies are presented in depth and a list of possible local and scientific criteria are identified in collaboration with stakeholders. Criteria are grouped by the technology's benefit or impact categories, as depicted by WOCAT: (a) production and socioeconomic, (b) sociocultural, (c) ecological, and (d) off-site benefits. Eventually, criteria of each category are ranked from the least to the most important according to stakeholder perception. Prominent technologies are also assigned scores per criterion for their expected effects on reducing soil degradation, related costs and benefits, and ecosystem services, also reflecting the degree to which these technologies are acceptable by stakeholders.

\subsection{Technology evaluation and selection}

A simplified version of the multi-criteria analysis (MCA) described in Mendoza et al. (2000) is used for the evaluation of each technology $t$ considering a set of criteria $c$ which, under the premise of the previous paragraph, fall within a single criteria category. Considering that criteria are ranked in ascending order of importance (i.e. 1 is the least important and $n$ is the most important of $n$ number of criteria), weights $\left(W_{\mathrm{c}}\right)$ can be assigned so that $\sum_{c=1}^{n} W_{\mathrm{c}}=1$. Per criterion, a technology is assigned a score $\left(S_{\mathrm{c}, \mathrm{t}}\right)$ which is taken into account weighted by $W_{\mathrm{c}}$ to estimate the cumulative score $S_{\mathrm{t}}$, such that

$S_{\mathrm{t}}=\sum_{c=1}^{n} W_{\mathrm{c}} \times S_{\mathrm{c}, \mathrm{t}}$

The result of this weighting allows technologies to be ranked per benefit category, assuming that categories themselves cannot be directly compared. For example, here we consider that, e.g., off-site benefits cannot be measured against sociocultural benefits, so a unique $S_{\mathrm{t}}$ is calculated per benefit category. In an effort for parsimony, here we ignore several aspects of decision analysis uncertainty (Scholten et al., 2015).

\section{Case study}

The Timpaki Basin is connected to the western Messara Plain by the Geropotamos River through the Phaistos Gorge and encompasses an area of $50 \mathrm{~km}^{2}$ located in the central-south 
area of Crete with a mean elevation of $200 \mathrm{~m}$. The topography of the basin is generally flat with steeper slopes in the northeast, with the highest point being part of the Psiloritis Mountain (Fig. 1). The climate ranges between sub-humid Mediterranean and semi-arid with mild moist winters (average temperature: $12^{\circ} \mathrm{C}$ ) and dry hot summers (average temperature: $23^{\circ} \mathrm{C}$ ), while the mean annual precipitation is around $500 \mathrm{~mm}$. As there is little surface water flow outside the winter months (Vardavas et al., 1997), groundwater is the main source of irrigation water and the key resource controlling the economic development of the region. Water shortage often occurs, due to temporal and spatial variations of precipitation, increased water demand during summer months, and the difficulty of transporting water due to the mountainous areas. Lately, there have been growing concerns over the possible depletion or deterioration of the groundwater quality due to intensive pumping beyond the safe yield of the basin (Tsanis and Apostolaki, 2008) and the gradual seawater intrusion (Paritsis, 2005; Vafidis et al., 2013). Despite measures for the protection of water resources imposed by the local water authority since 1984, implementation has faced difficulties mainly due to private wells (Kritsotakis and Tsanis, 2009).

Because of the favourable climatic conditions year-round, Timpaki is a highly exploited area concerning the greenhouse cultivations, even compared to the parent municipality of Phaistos (Table 1). Horticultural crops are dripirrigated almost exclusively from groundwater extraction; harvested twice a year; and mainly comprised of tomato (Solanum lycopersicum), cucumber (Cucumis sativus), zucchini (Cucurbita pepo), eggplant (Solanum melongena), pepper (Capsicum annuum), and green beans (Phaseolus vulgaris) (Thanopoulos et al., 2008). Here we address only tomato, the prevailing and most profitable horticultural crop under plastic. Tomato is moderately sensitive to salinity, able to withstand soil electrical conductivity (EC) up to $2.5 \mathrm{dS} \mathrm{m}^{-1}$ without significant yield losses $(\sim 10 \%)$ but suffering a $50 \%$ yield loss at $5.0 \mathrm{dS} \mathrm{m}^{-1}$ (Jones Jr., 2007).

Contrary to many rural areas in Greece that face the effects of urbanisation, the population of Timpaki has been steadily rising since the 1950 s, mainly due to the opportunities offered by the tourism sector in this coastal area (Fig. 2, left). Furthermore, there is evidence that suggests a motion of rural repopulation may have been activated in the country (Gkartzios and Scott, 2015). In Timpaki, land is mostly privately owned, and water rights can be public, cooperative, or private. The socio-economic gap among farmers is not too wide and more or less on par with those of the rest of the community which has faced a prolonged crisis leading to little overall investments and financial contraction (Fig. 2, right). Stakeholders often hold more than one role in the community, which often facilitates confrontation, either perpetuating or forcing conflicts to be resolved.

\subsection{Participatory selection of SLM technologies}

In the context of the RECARE project, Timpaki has been selected as a case study of the salinisation soil threat. As part of the stakeholder participation and valuation activities, 20 local and external stakeholders (including local and prefectural administrative authorities, agricultural technicians, farmers, scientists, and NGO representatives) participated in a local workshop in February 2015. Stakeholders were asked to (1) identify and group the primary constraints of greenhouse production linked to soil salinisation and to (2) discuss the list of potential technologies for addressing the soil salinisation threat from a user's point of view and select the most promising technologies currently applied. Criteria for selection included compatibility with current agricultural practices as well as sustainable investment and maintenance cost.

At a second workshop, stakeholders were invited to (1) assess promising technologies using criteria from the WOCAT QT and (2) reach a consensus regarding the perceived ranking of criteria of the same category. Through this process, promising technologies were assessed and selected using a participatory approach that combines collective learning with the application of a globally standardised documentation and evaluation framework as well as follow-up communication with experts. Table 2 presents a comprehensive list of empirical and literature prevention and amelioration technologies that have been applied to combat the soil salinisation threat, along with a representative reference. Table 2 also lists the type of measure according to WOCAT classification as well as the main prevention/amelioration strategy addressed by the respective technology (explained in Table 3). The next paragraphs thoroughly discuss the three most prominent technologies that surfaced from the participatory selection of the technologies listed in Table 2. These technologies were selected among already-applied approaches that were unanimously considered by stakeholders as "best practices" for greenhouse cultivation in the area.

\subsection{Technology 1 (T1): rainwater harvesting from greenhouse roofs}

Rainwater harvesting is one of the most ancient soil and water conservation and management technologies (AbdelKhaleq and Alhaj Ahmed, 2007). Nevertheless, applications are still current, often taking advantage of greenhouse structures (Islam et al., 2013; Ji et al., 2010) and explicitly practiced against soil salinity in greenhouses (Davies et al., 2011). The technology involves taking advantage of greenhouse roofs used as catchment areas for rainwater harvesting. Harvested rainwater is used for irrigation, either on its own or mixed with water from other sources. A network of gutters is installed to channel water into a storage tank that can be either above ground or at ground level, open or covered (Fig. 3). Reservoir size may be determined by various criteria, but the rule of thumb in the area is to construct 

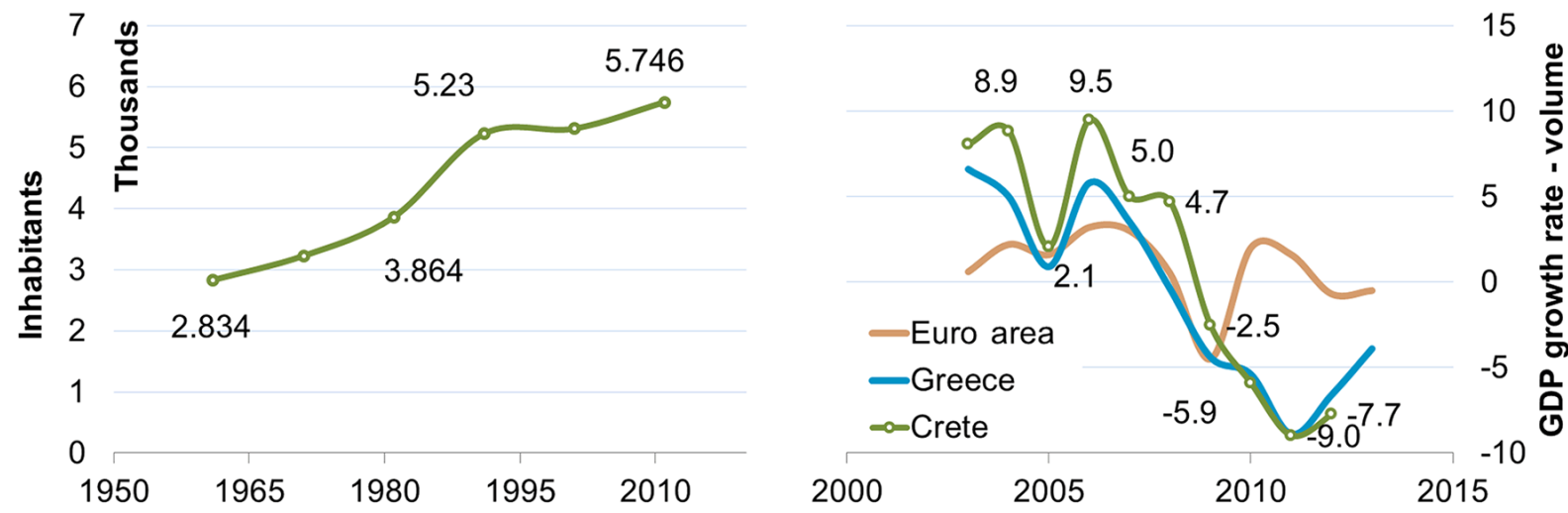

Figure 2. Left, population in Timpaki (Source: HSA, 2015); right, "real GDP growth rate - volume - percentage change on previous year" for the Euro area, Greece, and Crete (Source: EUROSTAT, 2015; HAS, 2015).

Table 1. Units in ha (\% of total). Source: HSA (2008).

\begin{tabular}{lllllll}
\hline Area & Olive trees & Arable crops* & Horticulture & Citrus & Vine trees & Total \\
\hline Timpaki & $1100(43 \%)$ & $1005(39 \%)$ & $401.5(16 \%)$ & $37(1 \%)$ & $3(0 \%)$ & 2540.2 \\
Phaistos & $13090(79 \%)$ & $1805(11 \%)$ & $1404.3(8 \%)$ & $187.5(1 \%)$ & $62.4(0 \%)$ & 16549.2 \\
\hline
\end{tabular}

* Major arable crops include watermelons, melon, and potatoes.

$300 \mathrm{~m}^{3} \mathrm{ha}^{-1}$ of greenhouse area. A cover may also be installed to reduce evaporation. Furthermore, a suitable pump and mixing facilities are installed to control water quality and quantity. During operation, a water filter and/or other water treatment may be required for removal of particles and waterborne-disease mitigation.

The technology promotes sustainable land management through prevention and mitigation of land degradation by increasing water resource self-sufficiency, thus allowing the user to rely less on the scarce groundwater resources and reducing the risk of soil salinisation and production failure. Furthermore, the technology improves the overall irrigation water quality, both on- and off-site. The main disadvantage of the technology, especially for the cultivation of tomatoes, which require irrigation water of moderate electric conductivity, is the increase of compensating agricultural inputs (i.e. fertilisers). This disadvantage can be mitigated by mixing freshwater with water from lower-quality sources (e.g. Malash et al., 2005). The technology requires average technical knowledge from both the agricultural advisor and the land user. Establishment costs include the construction of the preparation of the tank placement surface, the tank construction, the installation of the gutter network, and the installation of the pump and water sanitation measures. The majority of the greenhouses in the region have built-in gutters between the basic construction units in order to discharge rainwater from the roof for structural safety. Thus, few additional structural measures are required besides the construction of a reservoir system, such as a PVC-lined aboveground tank or artificial pond. Maintenance costs of the gutter network, the water storage tank, and the pump are negligible. Total costs amount to approximately EUR $14000 \mathrm{ha}^{-1}$ for a water storage that can cover at least $50 \%$ of the irrigation demand throughout the year, but this can vary depending on scale.

\subsection{Technology 2 (T2): crop rotation for green manuring in greenhouse}

Green manuring is also part of our global heritage of ancient agricultural practices (MacRae and Mehuys, 1985) and has been regaining attention as an organic farming soil amendment. The positive effects of green manuring on open-field vegetables are well documented (Beckmann, 1977; Chaves et al., 2004; MacRae and Mehuys, 1985; Stirling and Stirling, 2003; Thorup-Kristensen, 2006) and followed by modern greenhouse applications (Aghili et al., 2014; Duyar et al., 2008; Rose et al., 2015; Tüzel et al., 2013). Here, the angiosperm Sorghum vulgare used in greenhouse cultivations is suggested as green manure through crop rotation with tomato plants. The crop rotation usually takes place every other summer when local greenhouses remain otherwise fallow. Initially, when the main crop (tomatoes) is removed from the greenhouse in May/June, about $70 \mathrm{~kg} \mathrm{ha}^{-1}$ of sorghum seeds are sown and incorporated into the soil by ploughing at about $4-5 \mathrm{~cm}$ depth. Sorghum is drought- and heat-tolerant as well as moderately salt-tolerant (Netondo et al., 2004); thus the irrigation needs are minimal and depend on the respective climatic conditions. Water stress conditions may adversely 
Table 2. List of amelioration technologies for soil salinisation.

\begin{tabular}{|c|c|c|c|}
\hline Technology & SLM category $^{1}$ & Main benefits ${ }^{2}$ & Selected references \\
\hline Leaching (provided good drainage conditions) & A & A7 & Ali (2011), Qadir et al. (2000) \\
\hline Surface flashing & A & A7 & Qadir et al. (2000) \\
\hline Drip irrigation & $\mathrm{S}, \mathrm{A}$ & $\mathrm{A} 1, \mathrm{~A} 8$ & Ali (2011), Wan et al. (2007) \\
\hline Watering at night & M & $\mathrm{A} 1, \mathrm{~A} 8$ & empirical \\
\hline Increase of irrigation water every 3-4 watering events & $\mathrm{A}, \mathrm{M}$ & A7 & empirical \\
\hline Irrigation with saline water at less sensitive growth stages & A & A4 & $\operatorname{Ali}(2011)$ \\
\hline Mixing of saline and non-saline water & $\mathrm{M}, \mathrm{A}, \mathrm{S}$ & A5, & Ali (2011), Malash et al. (2005) \\
\hline Alternate/cyclic irrigation with saline and freshwater & $\mathrm{A}, \mathrm{S}$ & A4 & $\operatorname{Ali}(2011)$ \\
\hline Alternative water resources (e.g. reuse of wastewater) (e.g. T1) & $\mathrm{S}, \mathrm{M}$ & A5 & $\begin{array}{l}\text { Ali, (2011), Iannetta and } \\
\text { Colonna (2009) }\end{array}$ \\
\hline Desalination of irrigation water & $\mathrm{S}, \mathrm{M}$ & A5 & Iannetta and Colonna (2009) \\
\hline Mechanical removal of salt surface salt crust & $A, S$ & A7 & Ali (2011), Qadir et al. (2000) \\
\hline Careful use of machinery (no heavy machinery) & M & $\mathrm{A} 2, \mathrm{~A} 3$ & Iannetta and Colonna (2009) \\
\hline Green manuring - mulching with manure (e.g. T2) & A & $\mathrm{A} 2, \mathrm{~A} 3$ & $\begin{array}{l}\text { Ali, (2011), } \\
\text { Chatzigiannakis et al. (2012) }\end{array}$ \\
\hline Use of compost or other organic soil amendments & A, M & $\mathrm{A} 1, \mathrm{~A} 3$ & $\begin{array}{l}\text { Chatzigiannakis et al. (2012), } \\
\text { Oo et al. (2015), } \\
\text { Srivastava et al. (2014) }\end{array}$ \\
\hline Mulching with leaves/bark or other material & $\mathrm{S}, \mathrm{A}$ & $\mathrm{A} 1, \mathrm{~A} 7$ & $\begin{array}{l}\text { Al-Dhuhli et al. (2010), } \\
\text { Ali (2011), Mao et al. (2014) }\end{array}$ \\
\hline Use of inorganic amendments (e.g. Si, $\mathrm{CaSO}_{4} 2 \mathrm{H}_{2} \mathrm{O}, \mathrm{H}_{2} \mathrm{SO}_{4}$ ) & A & $\mathrm{A} 3, \mathrm{~A} 4, \mathrm{~A} 8$ & $\begin{array}{l}\text { Ahmad et al. (2013), } \\
\text { Matichenkov and } \\
\text { Kosobrukhov (2004) }\end{array}$ \\
\hline Biological reduction (phytoremediation or bioremediation) & $\mathrm{A}, \mathrm{V}, \mathrm{M}$ & A4 & $\begin{array}{l}\text { Ahmad et al. (2013), Ashraf et } \\
\text { al. (2010), Qadir et al. (2007) } \\
\text { Singh et al. (2015) }\end{array}$ \\
\hline Introduction of salinity- and hypoxia-tolerant plants & $\mathrm{M}, \mathrm{V}$ & $\mathrm{A} 1, \mathrm{~A} 3, \mathrm{~A} 7$ & Ali (2011), Qadir et al. (2000) \\
\hline Land use change from irrigated to rainfed & $\mathrm{M}, \mathrm{V}, \mathrm{A}$ & A5 & Iannetta and Colonna (2009) \\
\hline Implementation of drainage systems & $\mathrm{S}$ & $\mathrm{A} 2, \mathrm{~A} 7$ & $\begin{array}{l}\text { Ali (2011), } \\
\text { Chatzigiannakis et al. (2012) }\end{array}$ \\
\hline Intervention to the nutrition of plants (e.g. fertilisers) & A & A4 & $\begin{array}{l}\text { Flores et al. (2004), } \\
\text { NavarroPedreno et al. (1996) }\end{array}$ \\
\hline Drought pre-treatment of seedlings or seeds with $\mathrm{NaCl}$ & A & A4 & Cayuela et al. (2007) \\
\hline Grafting seedling on proper rootstock & A & A4 & $\begin{array}{l}\text { Estañ et al. (2005), } \\
\text { Fernández-García et al. (2004) }\end{array}$ \\
\hline Inoculation with mycorrhizal associations (e.g. T3) & A & A4 & Copeman et al. (1996) \\
\hline Bio-priming with biological agents (e.g. T3) & A & A4 & Rawat et al. (2011) \\
\hline Pre-sowing (or pre-plant) irrigation & $\mathrm{A}, \mathrm{M}$ & A4 & Ali (2011) \\
\hline
\end{tabular}

A: agronomic; M: management; S: structural; V: vegetative; T1, T2, and T3 are explained in the text. ${ }^{1}$ SLM measure category after WOCAT. ${ }^{2}$ As explained in Table 3.

affect grain production but promote root system expansion; thus improving soil structure is in this case favourable. Before the beginning of the tomato season in September, the farmer uses a branch grinder to fritter the sorghum plants and then incorporates them into the soil by tillage (Fig. 4). At this time the sorghum is still at a soft dough stage (Vanderlip, 1993), so a $20 \mathrm{~cm}$ deep tillage is enough to dispatch the rooting system, and immature grains will not grow back in the greenhouse. The process also needs to be well scheduled to provide enough time for greenhouse sanitation before planting tomatoes.

The technology is applied as an effective agronomic measure for the increase of soil productive capacity, the reduc- tion of pests and soil-borne parasites such as nematodes (Gardiano et al., 2014; Ortiz et al., 2015), and the mitigation of soil salinity (Netondo et al., 2004). This technology mitigates and prevents soil degradation by improving the soil and subsoil structure through the deep root system of sorghum (often $>1 \mathrm{~m}$ for mature crops) and increasing nutrient and organic matter availability through the incorporation of the plant biomass into the soil by tilling it under. Furthermore, organic amendments favour soil hydrology and structure (Yazdanpanah et al., 2016), thus mitigating salt accumulation in the root zone. The technology requires little technical knowledge from both the agricultural advisor and the land user. The increase of workload and the demand of 


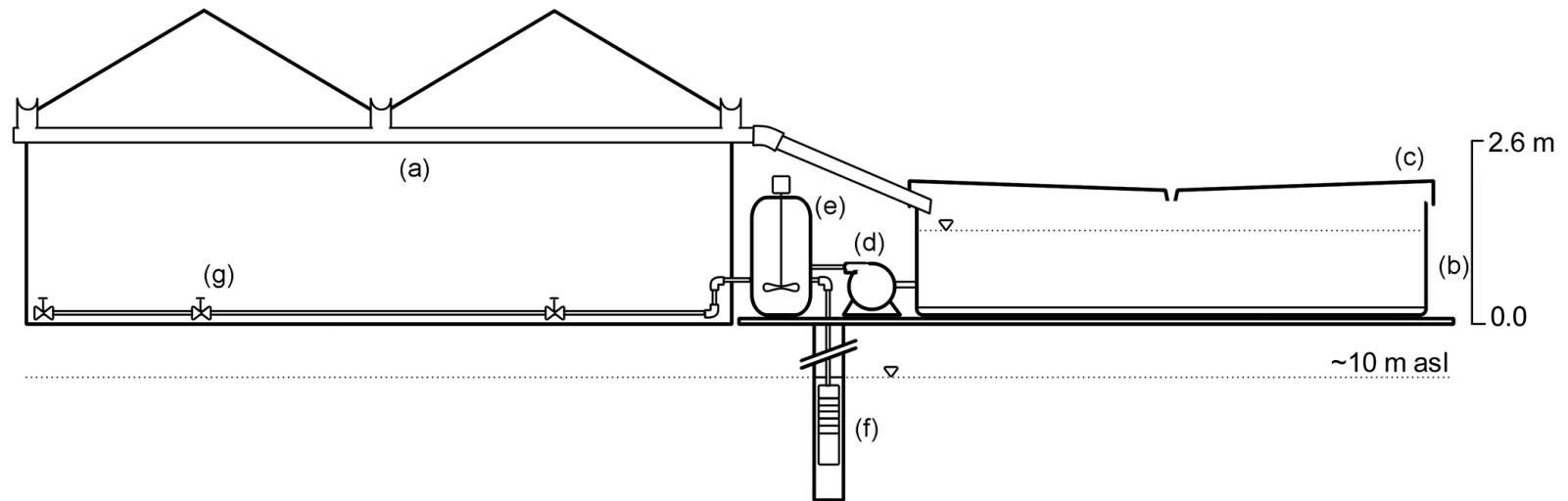

Figure 3. A network of gutters (a) channels rainwater into a reservoir facility (b) that can be optionally covered (c). The stored water is then pumped (d) into a mixing tank (e) where it dilutes the saline groundwater pumped from the aquifer (f). Reduced-salinity water is then directed to the irrigation system $(\mathrm{g})$ of the greenhouse.

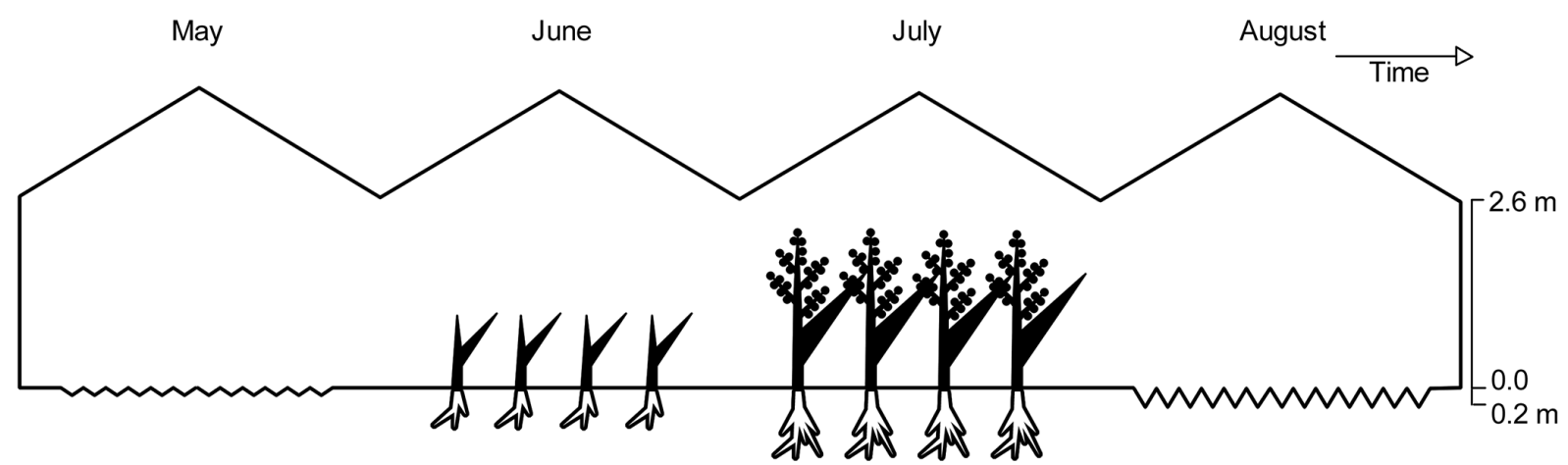

Figure 4. Sorghum rotation, from seeded in May to incorporation in the soil in August using a tiller.

Table 3. Intervention strategies of salinisation amelioration technologies.

\begin{tabular}{ll}
\hline Symbol $^{*}$ & Measure goal \\
\hline A1 & $\begin{array}{l}\text { Decrease of evaporation - conserve soil } \\
\text { water content }\end{array}$ \\
A2 & Increase drainage \\
A3 & Improve of soil quality structure \\
A4 & Adaptation: increase of plants salt \\
& resistance or decrease of plants salt \\
& accumulation \\
A5 & Improve irrigation water quality \\
A6 & Depression of groundwater table \\
A7 & Decrease soil salt accumulation \\
A8 & Reduce irrigation water application \\
\hline
\end{tabular}

* As used in Table 2.

irrigation water during the dry summer period constitute the main drawbacks of this technology. Otherwise, it has negligible establishment costs in the sense that it can be part of the usual farming practices but requires maintenance and recurrent activity costs such as seed and sowing costs, irrigation, and machine hours for reducing branch length with a branch grinder and incorporating sorghum into the soil with a tiller, which can amount to EUR $1000 \mathrm{ha}^{-1}$ every 2 years mainly due to labour (i.e. for small-scale farmers personal effort is usually sufficient for the application of the technology, and the only cost is that of seeds and machine rental, or about EUR $200 \mathrm{ha}^{-1}$ ).

\subsection{Technology 3 (T3): application of biological agents to increase crop resistance to salinity}

The Trichoderma ssp. fungus and various types of symbiotic associations of mycorrhizae are used in greenhouse cultivations in order to mitigate the impacts of salinity on crops and to improve existing soil properties. These biological agents are supplied commercially as soil amendments, and specific treatments vary according to cultivation type. The implementation of biological agents usually takes place once per plant as the microorganisms coexist with the plant (symbiotic association) and can be performed in different stages of the crop cultivation, depending on the commercial product, e.g. as a solution in the irrigation water; as a solid soil amendment in the early growing stages (Fig. 5); or, optimally, at the plant 


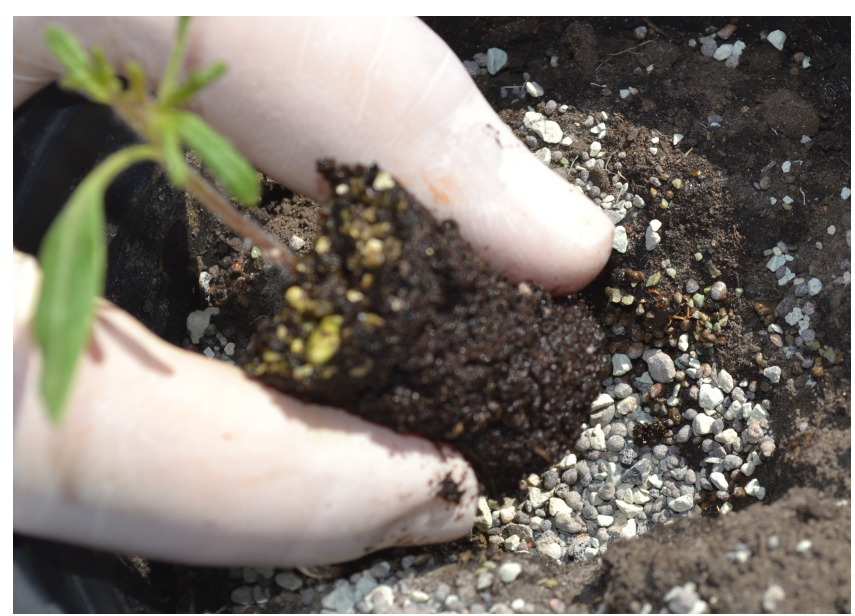

Figure 5. Mycorrhiza supplement in the form of grey aggregates used during tomato transplantation.

nursery (seed bio-priming) or during planting (plant inoculation). Biological agents require increased organic matter in the soil; absence of toxic substances (e.g. copper, fungicides, and pesticides); and, depending on agent type, suitable soil moisture and temperature. Here we investigate the effects of biological agents in tomato plantations, which are implemented in the early growing stages through irrigation.

The technology is applied as an effective agronomic measure for the increase of plants' salt tolerance, the reduction of soil-borne diseases that affect plant roots, and increase of water and nutrient absorption. This technology prevents or mitigates soil degradation by improving the subsoil structure by causing plant root system expansion and increase of the ability of the plant to absorb phosphates and micronutrients (Altomare et al., 1999). This effect can potentially decrease agricultural inputs (water and fertilisers) up to $40 \%$. An additional benefit is the maintenance and increase of subsoil fauna diversity and the subsequent biodegradation. The improved soil structure promotes higher infiltration rates, mitigates the salt accumulation in the root zone, and combats soil salinity, one of the main soil degradation problems in the coastal zone. Finally, the application of biological agents helps to keep the plants healthy, thus leading to increased crop yield and reduced production risk. The technology requires high technical knowledge on the part of the agricultural advisor but little from the side of the land user. The technology has negligible establishment costs since it can be part of the usual farming practices but requires the recurrent activity costs of inoculation with the selected biological agent. For an annual application of a biological agent the total cost is on average EUR $3000 \mathrm{ha}^{-1}$ year $^{-1}$ depending on expert advice.

\section{Results and discussion}

\subsection{Technology evaluation}

A first interpretation of results (Table 4) shows that $\mathrm{T} 1$ is the only technology that directly contributes to the reduction of soil salinity, whereas T2 and T3 have an indirect effect but also act as soil amendments, thus enhancing other soil functions in the process. Due to the immediate effect of freshwater application, it is safe to say that rainwater harvesting (T1) is the scientifically and ecologically optimal solution for conditions of extremely saline soil, whereas $\mathrm{T} 2$ and T3 do require some levels of soil fertility in order to produce results. The use of rainwater harvesting (T1) provides a degree of water autonomy, thus providing farmers with a sense of security for optimising or diversifying production. Additional value is derived by conflict mitigation within the community through the off-site benefit of overall increase of water availability. Disadvantages include soil sealing of fertile soil, thus reducing cultivated space, and the contingency on climatic conditions (precipitation/evaporation). Nevertheless, the latter is minor since during dry years the storage tank can be used as a basic buffer for other sources of water, and the application of covers, shading solutions (Hassan et al., 2015), or wind shelters (Hipsey and Sivapalan, 2003) can reduce evaporation. The significant reservoir installation cost and accommodation are the limiting factors and indeed the largest deterrent, especially for small-property owners. The economic feasibility of rainwater harvesting for irrigation has also been investigated by Liang and van Dijk (2011), who highlighted the importance of low pricing of groundwater that can render the investment in small and medium rainwater-harvesting systems less attractive. Under the current circumstances, the net profit from this investment may be positive only for large-property owners or after long-term use. It is estimated that only $5 \%$ of land users in the area own a water-harvesting system and about $70 \%$ have constructed it using external material support. Nevertheless, if groundwater and soil salinisation become prohibitive for cultivation, it is certain that a rainwater-harvesting system per greenhouse will no longer be optional.

The use of green manuring (T2) effectively decreases the required amounts of fertilisers and pesticides, therefore leading to a healthier soil in a sustainable way. Based on the practical experience, the cost of the technology is more or less self-sustained (i.e. the additional costs and workload are compensated by the reduced agricultural inputs during the growing season). The requirement of machinery (branch grinder, tiller) that is not used full-time for greenhouse operations (therefore their purchase cannot be easily justified for a small land owner) is viewed as a disadvantage that is hard to overcome if this machinery is not readily available for lending or renting. Moreover, the technology increases workload during a period where the greenhouse is otherwise fallow and would allow a part-time farmer to earn an off- 
Table 4. Comparison of the ecosystem and human well-being impacts of each technology along with average ranking of each benefit according to stakeholders.

\begin{tabular}{|c|c|c|c|c|c|}
\hline & Rank & $\begin{array}{r}\text { Weight } \\
\left(W_{\mathrm{B}}\right)\end{array}$ & $\mathrm{T} 1$ & $\mathrm{~T} 2$ & $\mathrm{~T} 3$ \\
\hline \multicolumn{6}{|l|}{ Production and socio-economic benefits } \\
\hline Increased irrigation water availability quality & 4 & 0.19 & +++ & & \\
\hline Reduced risk of production failure & 5 & 0.24 & ++ & & ++ \\
\hline Increased crop yield & 3 & 0.14 & + & + & ++ \\
\hline Reduced expenses on agricultural inputs & 6 & 0.29 & --- & + & ++ \\
\hline Reduced workload & 1 & 0.05 & & - & \\
\hline Reduced demand for irrigation water & 2 & 0.10 & & - & ++ \\
\hline \multicolumn{6}{|l|}{ Socio-cultural benefits } \\
\hline Conflict mitigation & 1 & 0.33 & ++ & & \\
\hline Improved food security/self-sufficiency & 2 & 0.67 & + & & \\
\hline \multicolumn{6}{|l|}{ Ecological benefits } \\
\hline Increased water quantity/quality & 9 & 0.20 & +++ & & \\
\hline Improved harvesting/collection of water & 7 & 0.16 & +++ & & \\
\hline Reduced soil salinity & 8 & 0.18 & +++ & + & + \\
\hline Increased biomass above-ground $\mathrm{C}$ & 4 & 0.09 & & ++ & + \\
\hline Increased nutrient cycling recharge & 6 & 0.13 & & ++ & \\
\hline Increased soil organic matter/below-ground C & 5 & 0.11 & & ++ & + \\
\hline Increased soil moisture & 3 & 0.07 & & + & \\
\hline Increased biological pest/disease control & 1 & 0.02 & & + & ++ \\
\hline Increased beneficial species (soil biodiversity) & 2 & 0.04 & & & +++ \\
\hline \multicolumn{6}{|l|}{ Off-site benefits } \\
\hline Increased water availability & 1 & 1.00 & ++ & & \\
\hline
\end{tabular}

$(+++)$ : very positive; $(++)$ : moderately positive; $(+)$ : slightly positive; $(-)$ : slightly negative; $(--)$ : moderately negative; $(---)$ : very negative.

farm income (e.g. from tourism). It is worth mentioning that only one farmer in the area practices this technology and had the opportunity to present it to other stakeholders during the workshop. From their side, stakeholders found the technology and its conveyed results very promising and worth further investigation to better identify adoption benefits.

The use of biological agents as crop growth and salinity tolerance amendments (T3) greatly improves crop production and overall soil functions. Significant advantages of this technology include the wide variety of biological agents, and their versatility and adaptability (Harman et al., 2004) that allow technicians to tailor application to the specific needs of each cultivation and user. The technology is simple to implement and generates little additional workload for the end user. Even though the cost of the inoculated plants or respective soil amendments is significant, the technology is applied by at least $15 \%$ of the local users, thus underlining the fact that annual benefits balance out costs. The local farmers' union may provide the opportunity to scale down high initial costs by placing bulk orders.

\subsection{Criterial importance and scoring}

A second reading of the results based on individual criterial importance reveals a different narration. Reduced expenses on agricultural inputs and risk of production failure predominate other production and socio-economic criteria in the value system of stakeholders (Table 4). This preference largely counterbalances other benefits of this category yielded by $\mathrm{T} 1$, bringing it on par with those offered by $\mathrm{T} 2$ and much lower than those offered by T3 (Fig. 6). While T1 remains the most all-inclusive solution, it becomes apparent that for the financially conservative dominated sample (low input, low risk) investing in this technology does not seem optimal. Since full costs for adopting T1 have to be borne in advance, the dynamics and uncertainty about the remaining soil resilience to mismanagement interact to generate an "option value" associated with postponing T1 (Ghadim and Pannell, 1999). On the other hand, T3 scores higher in the production and socio-economic criteria domain (Fig. 6).

Regarding the three other criteria categories, $\mathrm{T} 1$ still yields the highest impact in terms of significant criteria for sociocultural, ecological, and off-site benefits (Table 4). It is also notable that stakeholders value food security and water quality most, while the least valued criteria are pest species, soil 


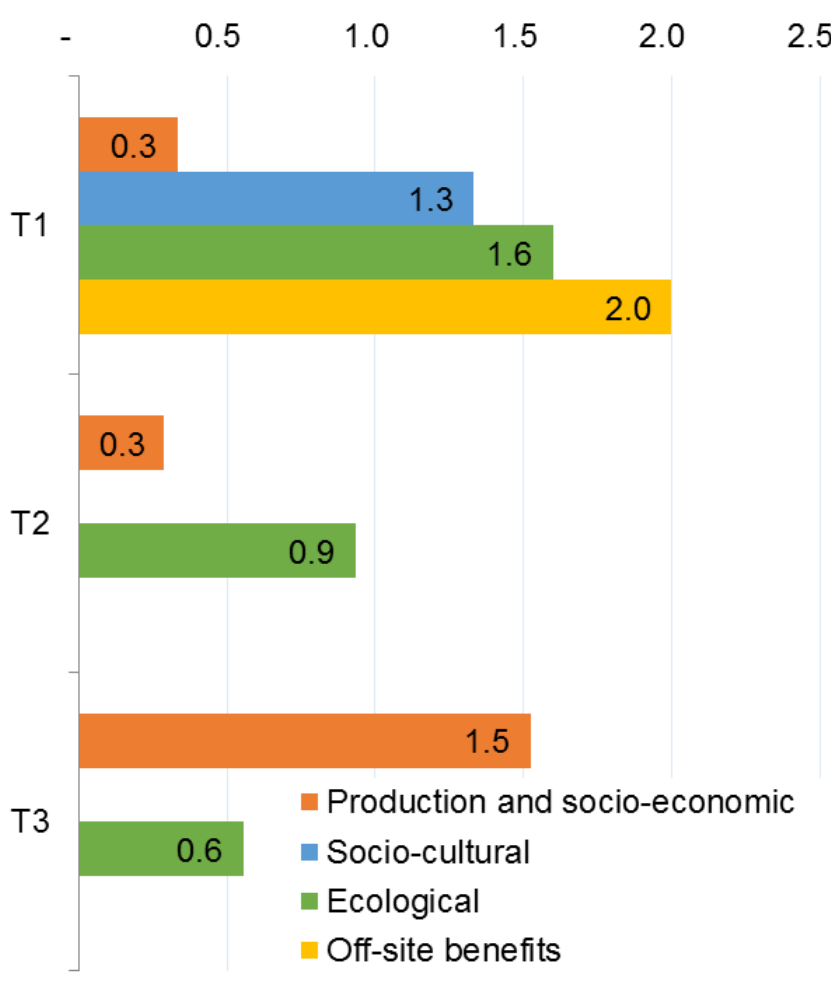

Figure 6. Cumulative score $\left(S_{\mathrm{c}}\right)$ per benefit category for the three technologies assessed.

biodiversity, and soil moisture, as greenhouse practices usually keep these factors under close control. Stakeholder preference for food security over conflict mitigation suggests a fragmented society with little coordination and low capacity of adaptation, which is not typical for rural Greece. Nevertheless, stakeholders are the least interested in reducing workload, suggesting a high level of diligence and commitment.

\section{Conclusions}

The variety and multidisciplinarity of the stakeholders participating in the workshop allowed for an in-depth discussion on the three most promising technologies proposed by stakeholders and a comparative analysis driven by the WOCAT QT process. Using a participatory approach and the impact criteria from QT (advantages and disadvantages), the impacts of each technology on the ecosystem and human well-being were identified and evaluated (Table 4). WOCAT effectively documented SLM technology strengths and weaknesses according to expert and stakeholder opinion, along with proposed steps for sustaining and enhancing merits or mitigating inefficiencies. Based on the results of this application and the feedback of participants, the methodology facilitates effective multi-stakeholder learning processes (especially in the case of T2) that contribute to more sustainable management of land.
In the Timpaki case study it is obvious that stakeholders have a preference towards technologies that promote existing cultivations, rather than more salt-tolerant crops or alternative land use, signifying the lifelong commitment to the land and their products. To underline the existence of expertise, there are indeed examples where the joint effort of technicians and farmers with adequate investment funds has succeeded with exceptional results. Discussions revealed that certain farmers are well aware of SLM practices and are open to sharing their know-how. Nevertheless, the majority is forced to make short-term plans and focus on short-term profit maximisation due to financial circumstances and other externalities. To some extent, the three documented technologies promote sustainable agriculture management (soil protection and conservation) and reduce production failure risk and soil salinity. Even though a direct comparison is challenging, WOCAT has enabled researchers and users to rank technology impacts during the joint workshop. Results showed that T2 and T3 have a relatively low recurrent cost and almost direct return but do not present a direct solution to the soil salinity threat. As a consequence, their applicability and effectiveness may gradually decline as soil salinity increases. On the other hand $\mathrm{T} 1$ provides a long-term solution that enables the use of additional technologies and generates returns beyond the annual production. Above soil sustainability, the wide implementation of rainwater harvesting is bound to greatly reduce water use conflicts, thus contributing to the general well-being of the local community.

The negligible spontaneous trend towards adoption of $\mathrm{T} 1$ can be largely attributed to the high establishment cost and the negligible impact of agricultural input reduction compared to T2 and T3 (i.e. financial returns may not be immediately apparent). Results support the hypothesis that stakeholders tend to embrace agronomic and management measures, non-capital intensive actions, and possibly ephemeral approaches against the soil salinisation threat. This can be partly explained by a preference to adapt rather than mitigate and to offset costs of an otherwise uncertain outcome. Findings also have to be interpreted in the context of the current socio-economic conditions that have augmented financial uncertainty. Recent research by Micha et al. (2015) has highlighted the role of the financial crisis along with a range of social factors in decision making of Greek farmers.

Even though word of mouth conveys the successful results, users are willing to adopt the technology only if external material support is provided. Insight attained during the workshop points to a pattern of technology adoption where a "pioneer" applied a technology first, but the majority of users will follow only when they have run out of well-established options. Another explanation is that, for more permanent and costly solutions, stakeholders tend to anticipate structural and policy solutions to be implemented by the central government. This often means that the system is already on the verge of collapse. Possible solutions to meet this challenge half-way may be for local government to provide incentives 
(i.e. to subsidise the technology) or to make it an obligatory requirement for greenhouse operation.

Acknowledgements. The research leading to these results has received funding from the European Union Seventh Framework Programme (FP7/2007-2013) under grant agreement no. 603498 (RECARE). The authors would also like to acknowledge the valuable suggestions and contribution of Konstantinos Nikoloudis and Evangelos Gibragakis.

Edited by: A. Cerdà

\section{References}

AbdelKhaleq, R. A. and Alhaj Ahmed, I.: Rainwater harvesting in ancient civilizations in Jordan, Water Sci. Technol., 7, 85-93, doi:10.2166/ws.2007.010, 2007.

Abu Hammad, A. and Tumeizi, A.: Land degradation: socioeconomic and environmental causes and consequences in the eastern Mediterranean, Land Degrad. Dev., 23, 216-226, 2012.

Aghili, F., Gamper, H. A., Eikenberg, J., Khoshgoftarmanesh, A. H., Afyuni, M., Schulin, R., Jansa, J., and Frossard, E.: Green manure addition to soil increases grain zinc concentration in bread wheat, PLoS ONE, 9, e101487, doi:10.1371/journal.pone.0101487, 2014.

Ahmad, S., Ghafoor, A., Akhtar, M., and Khan, M.: Ionic displacement and reclamation of saline-sodic soils using chemical amendments and crop rotation, Land Degrad. Dev., 24, 170-178, 2013.

Al-Dhuhli, H. S., Al-Rawahy, S. A., and Prathapar, S.: Effectiveness of mulches to control soil salinity in sorghum fields irrigated with saline water, in: the Monograph on Management of SaltAffected Soils and Water for Sustainable Agriculture, edited by: Mushtaque, A., Al-Rawahi, S. A., and Hussain, N., Sultan Qaboos University, Oman, 41-46, 2010.

Ali, H.: Practices of Irrigation \& On-farm Water Management: Volume 2. Springer Science \& Business Media, 2011.

Altomare, C., Norvell, W., Björkman, T., and Harman, G.: Solubilization of phosphates and micronutrients by the plant-growthpromoting and biocontrol fungus Trichoderma harzianum Rifai 1295-22, Appl. Environ. Microbiol., 65, 2926-2933, 1999.

Ashraf, M. Y., Ashraf, M., Mahmood, K., Akhter, J., Hussain, F., and Arshad, M.: Phytoremediation of saline soils for sustainable agricultural productivity, in: Plant Adaptation and Phytoremediation, Springer, 335-355, 2010.

Beckmann, E.: Effects of long-term green manuring on soil fertility in vegetable production with special reference to phyto-hygienic aspects, Qual. Plant., 27, 59-83, 1977.

Berendse, F., van Ruijven, J., Jongejans, E., and Keesstra, S.: Loss of Plant Species Diversity Reduces Soil Erosion Resistance, Ecosystems, 18, 881-888, 2015.

Bowmer, K.: Water resources in Australia: deliberation on options for protection and management, Australas. J. Environ., 21, 228240, 2014

Brevik, E., Cerdà, A., Mataix-Solera, J., Pereg, L., Quinton, J., Six, J., and Van Oost, K.: The Interdisciplinary Nature of Soil, Soil, 1, 117-129, 2015.
Cayuela, E., Muñoz-Mayor, A., Vicente-Agulló, F., Moyano, E., Garcia-Abellan, J. O., Estañ, M. T., and Bolarín, M. C.: Drought pretreatment increases the salinity resistance of tomato plants, $\mathrm{J}$. Plant Nutrit. Soil Sci., 170, 479-484, 2007.

Chatzigiannakis, E., Ilias, A., and Panoras, A.: Guide to address the loss of organic matter, salinisation, acidification and the erosion of agricultural soils, in: The scope of Project LIFE So.S. Thessaloniki, Greece, 2012.

Chaves, B., De Neve, S., Hofman, G., Boeckx, P., and Van Cleemput, O.: Nitrogen mineralization of vegetable root residues and green manures as related to their (bio) chemical composition, $\mathrm{Eu}-$ rop. J. Agron., 21, 161-170, 2004.

Chesworth, W.: Encyclopedia of soil science, edited by:Chesworth, W., ISBN: 978-1-4020-3994-2, Publisher Springer Netherlands, Springer, 902 pp., 2008.

Copeman, R. H., Martin, C. A., and Stutz, J. C.: Tomato growth in response to salinity and mycorrhizal fungi from saline or nonsaline soils, HortScience, 31, 341-344, 1996.

Daliakopoulos, I. and Tsanis, I.: Greece: Agro-pastoral overexploitation and its implications in Messara Valley (Crete), in: CIHEAM Watch Letter No28 "Land Issues in the Mediterranean Countries.”, Paris, CIHEAM, April 2014, ISSN 2114 3129, 2014.

Daskalaki, P. and Voudouris, K.: Groundwater quality of porous aquifers in Greece: a synoptic review, Environ. Geol., 54, 505513, 2008.

Davies, P. A., Hossain, A. K., Igobo, O. N., Garantziotis, G., Srivastava, R., and Kaphaliya, B.: A greenhouse integrating desalination, water saving and rainwater harvesting for use in saltaffected inland regions, J. Scient. Indust. Res., 70, 628-633, 2011.

Domínguez-Beisiegel, M., Herrero, J., and Castañeda, C.: Saline Wetlands' Fate in Inland Deserts: an Example of 80 Years' decline in Monegros, Spain, Land Degrad. Deve., 24, 250-265, 2013.

Dubois, G., Cornford, D., Hristopulos, D., Pebesma, E., and Pilz, J.: Editorial: Introduction to this special issue on geoinformatics for environmental surveillance, Comput. Geosci., 37, 277-279, 2011.

Duyar, H., Tüzel, Y., Gürbüz Kılıc, O., and Anac, D.: The Effects of Green Manuring on Organic Head Lettuce Production in Greenhouse, in: International Symposium on Strategies Towards Sustainability of Protected Cultivation in Mild Winter Climate 807, 365-370, 2008.

EEA: Groundwater quality and quantity in Europe, Environmental assessment report, European Environment Agency, Copenhagen, 1999.

Estañ, M. T., Martinez-Rodriguez, M. M., Perez-Alfocea, F., Flowers, T. J., and Bolarin, M. C.: Grafting raises the salt tolerance of tomato through limiting the transport of sodium and chloride to the shoot, J. Experim. Bot., 56, 703-712, 2005.

EUROSTAT: Real GDP growth rate - volume - Percentage change on previous year, available at: http://ec.europa.eu (last access: 1 January 15), 2015.

Fernández-García, N., Martínez, V., and Carvajal, M.: Effect of salinity on growth, mineral composition, and water relations of grafted tomato plants, J. Plant Nutrit. Soil Sci., 167, 616-622, 2004. 
Flores, P., Botella, M.Á., Cerdá, A., and Martínez, V.: Influence of nitrate level on nitrate assimilation in tomato (Lycopersicon esculentum) plants under saline stress, Can. J. Bot., 82, 207-213, 2004.

Gardiano, C. G., Krzyzanowski, A. A., Saab, O.: Efficiency of green manure species on the population of reniform nematode, Semina: Ciências Agrárias (Londrina), 35, 719-726, 2014.

Geeson, N. A., Brandt, C. J., and Thornes, J. B.: Mediterranean desertification: a mosaic of processes and responses, John Wiley \& Sons, 2003.

Ghadim, A. K. A. and Pannell, D. J.: A conceptual framework of adoption of an agricultural innovation, Agr. Econ., 21, 145-154, 1999.

Gkartzios, M. and Scott, K.: A Cultural Panic in the Province? Counterurban Mobilities, Creativity, and Crisis in Greece, Population, Space and Place, 2015.

Harman, G. E., Howell, C. R., Viterbo, A., Chet, I., and Lorito, M.: Trichoderma species - opportunistic, avirulent plant symbionts, Nat. Rev. Microbiol., 2, 43-56, 2004.

Hassan, M., Peirson, W. L., Neyland, B. M., and Fiddis, N. M.: Evaporation mitigation using floating modular devices, J. Hydrol., 530, 742-750, 2015.

Hipsey, M. R. and Sivapalan, M.: Parameterizing the effect of a wind shelter on evaporation from small water bodies, Water Resour. Res., 39, 1-9, 2003.

Hornidge, A.-K., U1 Hassan, M., and Mollinga, P. P.: Transdisciplinary innovation research in Uzbekistan-one year of "Followthe-Innovation", Dev. Practice, 21, 834-847, 2011.

HSA: Annual Agricultural Statistics Report of the Hellenic Statistical Authority (ELSTAT), Hellenic Statistic Authority, 2008.

HSA: Population Census of Hellenic Statistical Authority (ELSTAT), Hellenic Statistic Authority, 2015.

Iannetta, M. and Colonna, N.: Salinisation in the Mediterranean context, Booklet in the framework of the VI Framework Programma Priorità 1, in: The Framework Of The Vi Framework Programma Priorità, 1.1.6.3 Global Change and Ecosystems, EU SSA Lucinda Project, 20 pp., 2009.

Illukpitiya, P. and Gopalakrishnan, C.: Decision-making in soil conservation: application of a behavioral model to potato farmers in Sri Lanka, Land Use Policy, 21, 321-331, 2004.

Islam, S., Lefsrud, M., Adamowski, J., Bissonnette, B., and Busgang, A.: Design, Construction, and Operation of a Demonstration Rainwater Harvesting System for Greenhouse Irrigation at McGill University, Canada, HortTechnology, 23, 220-226, 2013.

Ji, W., Cai, J., Wang, Z., and Wang, K.: Scale optimization of greenhouse agricultural rainwater harvesting and utilization project, T. Chin. Soc. Agr. Engin., 26, 248-253, 2010.

Jones, A., Panagos, P., Barcelo, S., Bouraoui, F., Bosco, C., Dewitte, O., Gardi, C., Hervás, J., Hiederer, R., and Jeffery, S.: The state of soil in europe-a contribution of the jrc to the european environment agency's environment state and outlook report-soer 2010, 2012.

Jones Jr., J. B.: Tomato plant culture: in the field, greenhouse, and home garden, CRC press, 2007.

Jones, R. J., Le Bissonnais, Y., Bazzoffi, P., Sanchez Diaz, J., Düwel, O., Loj, G., Øygarden, L., Prasuhn, V., Rydell, B., and Strauss, P.: Nature and extent of soil erosion in Europe, European Communities, 2003.
Keesstra, S., Geissen, V., Mosse, K., Piiranen, S., Scudiero, E., Leistra, M., and van Schaik, L.: Soil as a filter for groundwater quality, Curr. Opin. Environ. Sustain., 4, 507-516, 2012.

Kessler, C.: Decisive key-factors influencing farm households' soil and water conservation investments, Appl. Geogr., 26, 40-60, 2006.

Kritsotakis, M. and Tsanis, I.: An integrated approach for sustainable water resources management of Messara basin, Crete, Greece, Eur Water, 27, 15-30, 2009.

Lázár, A. N., Clarke, D., Adams, H., Akanda, A. R., Szabo, S., Nicholls, R. J., Matthews, Z., Begum, D., Saleh, A. F. M., and Abedin, M. A.: Agricultural livelihoods in coastal Bangladesh under climate and environmental change-A model framework, Environ. Sci., 17, 1018-1031, 2015.

Li, J., Pu, L., Zhu, M., and Zhang, R.: The present situation and hot issues in the salt-affected soil research, Acta Geogr. Sin., 67, 1233-1245, 2012.

Liang, X. and van Dijk, M. P.: Economic and financial analysis on rainwater harvesting for agricultural irrigation in the rural areas of Beijing. Resources, Conserv. Recycl., 55, 1100-1108, 2011.

Liniger, H. and Schwilch, G.: Enhanced decision-making based on local knowledge: The WOCAT method of sustainable soil and water management, Mount. Res. Dev., 22, 14-18, 2002.

Liniger, H. and Critchley, W.: Where the land is greener: Case studies and analysis of soil and water conservation initiatives worldwide, 2007.

Liu, G., Dai, F., Nan, L., and Du, S.: Assessing the suitability of soil and water conservation practices in Southwestern China, Land Use Pol., 30, 319-327, 2013.

Maas, E. V., Grattan, S. R., Skaggs, R. W., and van Schilfgaarde, J.: Crop yields as affected by salinity, in: Agricultural Drainage, Chap. 3, edited by: Skaggs, R. W. and van Schilfgaarde, J., American Society of Agronomy, 55-108, 1999.

MacRae, R. and Mehuys, G.: The effect of green manuring on the physical properties of temperate-area soils, in: Advances in Soil Science, Springer, 71-94, 1985.

Malash, N., Flowers, T., and Ragab, R.: Effect of irrigation systems and water management practices using saline and non-saline water on tomato production, Agr. Water Manage., 78, 25-38, 2005.

Mao, W., Kang, S., Wan, Y., Sun, Y., Li, X., and Wang, Y.: Yellow River Sediment as a Soil Amendment for Amelioration of Saline Land in the Yellow River Delta, Land Degrad. Dev., doi:10.1002/ldr.2323, 2014.

Mateo-Sagasta, J. and Burke, J.: Agriculture and water quality interactions: a global overview, SOLAW Background Thematic Report - TR08, 2011.

Matichenkov, V. and Kosobrukhov, A.: Si effect on the plant resistance to salt toxicity, Proceedings of the ISCO 13, 2004.

Mendoza, G., Macoun, P., Prabhu, R., Sukadri, D., Purnomo, H., and Hartanto, H.: Guidelines for applying multi-criteria analysis to the assessment of criteria and indicators, Application de l'analyse multicritere a l'evaluation des criteres et indicateurs, 2000.

Micha, E., Areal, F. J., Tranter, R. B., and Bailey, A. P.: Uptake of agri-environmental schemes in the Less-Favoured Areas of Greece: The role of corruption and farmers' responses to the financial crisis, Land Use Pol., 48, 144-157, 2015.

Montanarella, L.: Trends in land degradation in Europe, in: Climate and Land Degradation, Springer, 83-104, 2007. 
NavarroPedreno, J., Gomez, I., and Mataix, J.: Micronutrient concentration in tomato plants affected by salinity and organic waste fertilization, Agrochimica, 40, 257-262, 1996.

Netondo, G. W., Onyango, J. C., and Beck, E.: Sorghum and salinity, Crop Science, 44, 797-805, 2004.

OECD: Environmental Performance Reviews: Greece 2009, OECD publications, 2009.

Oo, A., Iwai, C., and Saenjan, P.: Soil Properties and Maize Growth in Saline and Nonsaline Soils using Cassava-Industrial Waste Compost and Vermicompost with or Without Earthworms, Land Degrad. Dev., 26, 300-310, 2015.

Ortiz, A. M., Sipes, B. S., Miyasaka, S .C., and Arakaki, A. S.: Green Manure Crops for Management of Meloidogyne javanica and Pythium aphanidermatum, HortScience, 50, 90-98, 2015.

Paritsis, S. N.: Simulation of seawater intrusion into the Tymbaki aquifer, South Central Crete, Greece. Report within MEDIS project, Study implemented on behalf of the Department of Management of Water Resources of the Region of Crete, Heraklion, Crete, Greece, 2005.

Posthumus, H. and Morris, J.: Implications of CAP reform for land management and runoff control in England and Wales, Land Use Pol., 27, 42-50, 2010.

Qadir, M., Ghafoor, A., and Murtaza, G.: Amelioration strategies for saline soils: a review, Land Degrad. Dev., 11, 501-521, 2000.

Qadir, M., Oster, J., Schubert, S., Noble, A., and Sahrawat, K.: Phytoremediation of sodic and saline-sodic soils, Adv. Agron., 96, 197-247, 2007.

Rawat, L., Singh, Y., Shukla, N., and Kumar, J.: Alleviation of the adverse effects of salinity stress in wheat (Triticum aestivum $L$.) by seed biopriming with salinity tolerant isolates of Trichoderma harzianum, Plant Soil, 347, 387-400, 2011.

Rengasamy, P.: World salinization with emphasis on Australia, J. Experim. Bot., 57, 1017-23, 2006.

Rose, T. J., Julia, C. C., Shepherd, M., Rose, M. T., and Van Zwieten, L.: Faba bean is less susceptible to fertiliser $\mathrm{N}$ impacts on biological $\mathrm{N}_{2}$ fixation than chickpea in monoculture and intercropping systems, Biol. Fertil. Soils, 52, 271-276, 2015.

Sattler, C. and Nagel, U. J.: Factors affecting farmers' acceptance of conservation measures - a case study from north-eastern Germany, Land Use Pol., 27, 70-77, 2010.

Scholten, L., Schuwirth, N., Reichert, P., and Lienert, J.: Tackling uncertainty in multi-criteria decision analysis-An application to water supply infrastructure planning, Europ. J. Operat. Res., 242, 243-260, 2015.

Schultz, B., Zimmer, D., and Vlotman, W. F.: Drainage under increasing and changing requirements, Irrigat. Drain., 56, S3-S22, 2007.

Schwilch, G., Bachmann, F., and Liniger, H.: Appraising and selecting conservation measures to mitigate desertification and land degradation based on stakeholder participation and global best practices, Land Degrad. Dev., 20, 308-326, 2009.

Schwilch, G., Bestelmeyer, B., Bunning, S., Critchley, W., Herrick, J., Kellner, K., Liniger, H., Nachtergaele, F., Ritsema, C., and Schuster, B.: Experiences in monitoring and assessment of sustainable land management, Land Degrad. Dev., 22, 214-225, 2011.

Singh, Y. P., Nayak, A. K., Sharma, D. K., Singh, G., Mishra, V., and Singh, D.: Evaluation of Jatropha curcas Genotypes for Re- habilitation of Degraded Sodic Lands, Land Degrad. Dev., 26, 510-520, 2015.

Sparks, D. L.: Environmental soil chemistry, Academic press, 352 pp., 2003.

Srivastava, P. K., Gupta, M., Singh, N., and Tewari, S. K.: Amelioration of sodic soil for wheat cultivation using bioaugmented organic soil amendment, Land Degrad. Dev., doi:10.1002/ldr.2292, 2014.

Stirling, G. and Stirling, A.: The potential of Brassica green manure crops for controlling root-knot nematode (Meloidogyne javanica) on horticultural crops in a subtropical environment, Anim. Prod. Sci., 43, 623-630, 2003.

Thanopoulos, R., Samaras, S., Ganitis, K., Gatzelaki, C., Kotaki, E., Psara, E., Kipriotakis, Z., Tzitzikas, E., Kalaitzis, P., Terzopoulos, P., and Mpempeli, P.: Local varieties of cultivated species in Crete emphasizing on vegetables, A potential for multiple use, Agriculture - Livestock, 2008.

Thorup-Kristensen, K.: Root growth and nitrogen uptake of carrot, early cabbage, onion and lettuce following a range of green manures, Soil Use Manage., 22, 29-38, 2006.

Tóth, G. and Li, X. (Eds): Threats to the Soil Resource Base of Food Security in China and Europe, Report EUR 25632 EN, A report from the. Sino-EU Panel on Land and Soil, ISBN 978-9279-27745-0, Luxembourg, Publications Office of the European Union, doi:10.2788/71196, 2013

Tóth, G., Montanarella, L., and Rusco, E.: Threats to soil quality in Europe, Institute for Environment and Sustainability, Ispra, 2008.

Tsanis, I. K. and Apostolaki, M. G.: Estimating Groundwater Withdrawal in Poorly Gauged Agricultural Basins, Water Resour. Manage., 23, 1097-1123, 2008.

Tüzel, Y., Duyar, H., Özteki n, G. B., Kiliç, Ö. G., Anac, D., Madanlar, N., and Yoldaş, Z.: Effects of winter green manuring on organic cucumber production in unheated greenhouse conditions, Turkish J. Agricul. Forest., 37, 315-325, 2013.

Vafidis, A., Soupios, P., Economou, N., Hamdan, H., Andronikidis, N., Kritikakis, G., Panagopoulos, G., Manoutsoglou, E., Steiakakis, M., Candansayar, E., and Schafmeister, M.: Seawater intrusion imaging at Tybaki, Crete, using geophysical data and joint inversion of electrical and seismic data, First Break Issue, 32, 107-114, 2013.

van Beek, C. L. and Tóth, G.: Risk Assessment Methodologies of Soil Threats in Europe, JRC Scientific and Policy Reports EUR 24097, 2012

van Camp, L., Bujarrabal, B., Gentile, A. R., Jones, R. J. A., Montanarella, L., Olazabal, C., and Selvaradjou, S.: Reports of the technical working groups established under the thematic strategy for soil protection, Office for Official Publications of the European Communities, 2004.

Vanderlip, R.: How a sorghum plant develops, Cooperative Extension Service, Kansas State University (1972), ASIN: B000735HXA, 19 pp., 1993.

Vardavas, I. M., Papamastorakis, J., Fountoulakis, A., and Manousakis, M.: Water resources in the desertificationthreatened Messara Valley of Crete: estimation of potential lake evaporation, Ecol. Modell., 102, 363-374, 1997.

Wan, S., Kang, Y., Wang, D., Liu, S.-P., and Feng, L.-P.: Effect of drip irrigation with saline water on tomato (Lycopersicon esculentum Mill) yield and water use in semi-humid area, Agr. Water Manage., 90, 63-74, 2007. 
Wauters, E., Bielders, C., Poesen, J., Govers, G., and Mathijs, E.: Adoption of soil conservation practices in Belgium: an examination of the theory of planned behaviour in the agri-environmental domain, Land Use Pol., 27, 86-94, 2010.

WOCAT: Questionnaire on SLM Technologies (Basic), A Framework for the Evaluation of Sustainable Land Management (revised), in: Centre for Development and Environment, edited by: Liniger, H. P., Schwilch, G., Gurtner, M., Mekdaschi Studer, R., Hauert, C., van Lynden, G., and Critchley, W., Institute of Geography, University of Berne, Berne, 2008.
WOCAT: Wocatnet, https://qt.wocat.net (last access: 1 December 2015), 2015.

Yazdanpanah, N., Mahmoodabadi, M., and Cerdà, A.: The impact of organic amendments on soil hydrology, structure and microbial respiration in semiarid lands, Geoderma, 266, 58-65, 2016. 